07

\title{
Фотоэлектрические преобразователи лазерного излучения на основе гетероструктур InP(GaAs)/InP, полученные методом жидкофазной эпитаксии
}

\author{
(C) Н.С. Потапович, Н.Х. Тимошина, В.П. Хвостиков \\ Физико-технический институт им. А.Ф. Иоффре РАН, Санкт-Петербург, \\ Россия \\ E-mail: nspotapovich@mail.ioffe.ru
}

Поступило в Редакцию 21 мая 2018 г.

Рассмотрена возможность создания методом жидкофазной эпитаксии фотопреобразователей лазерного излучения на основе гетероструктур $\operatorname{InP}(\mathrm{GaAs}) / \mathrm{InP}$, предназначенных для использования в системах беспроводной передачи энергии по лазерному лучу на длинах волн $\lambda \approx 1.06-1.2 \mu \mathrm{m}$.

DOI: 10.21883/PJTF.2018.18.46609.17397

Системы с беспроводной передачей энергии привлекают к себе все большее внимание отечественных и зарубежных исследователей [1-3]. С точки зрения создания эффективных систем передачи энергии по лазерному лучу значительный интерес представляет преобразование монохроматического излучения с длиной волны $\lambda=1.064 \mu \mathrm{m}[4,5]$, на которой работает, например, $\mathrm{Nd}-\mathrm{YAG}$-лазер, обладающий относительно малой расходимостью луча. Наиболее перспективным материалом для создания методом жидкофазной эпитаксии (ЖФЭ) фотоэлектрических преобразователей (ФЭП), работающих в диапазоне длин волн 1.0-1.3 $\mu \mathrm{m}$, являются гетероструктуры InGaAsP/InP [6]. Настоящая работа посвящена разработке и исследованию таких гетероструктур и ФЭП на их основе (рис. $1, a, b)$, предназначенных для преобразования лазерного излучения на длинах волн $\lambda=1.064$ и $1.2 \mu$ т и для использования их в последующем в системах с беспроводной передачей энергии.

Гетероструктуры InP(GaAs)/InP выращивались методом жидкофазной эпитаксии в атмосфере водорода в графитовой кассете слайдерного типа из расплава индия чистотой $5 \mathrm{~N}$. В качестве подложки исполь- 


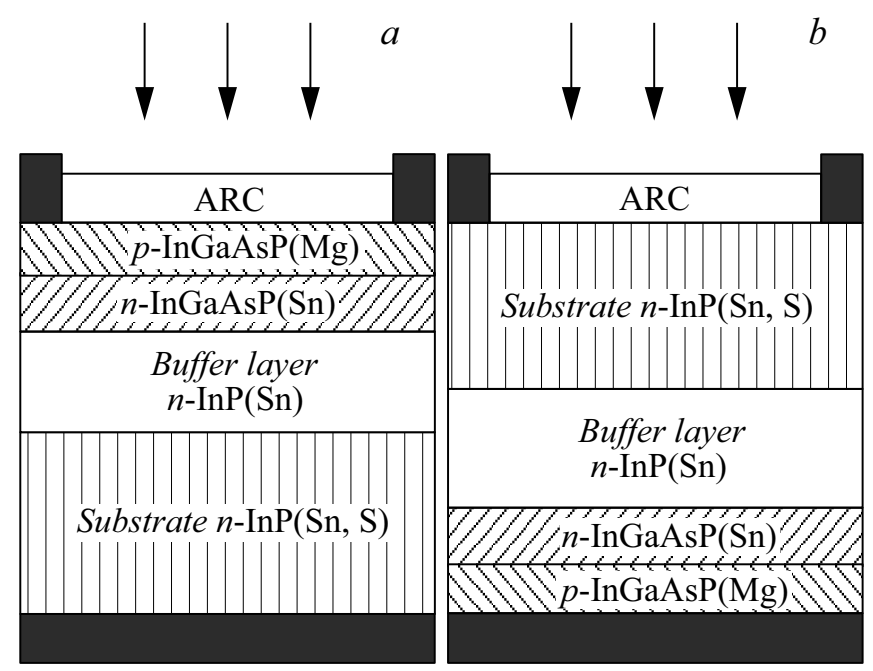

Pис. 1. Структура фотоэлектрического преобразователя лазерной энергии на основе гетероструктуры $\operatorname{InP}(\mathrm{GaAs}) / \mathrm{InP} . a$ - для случая „прямой“ засветки, $b-$ для случая „инверсной“ засветки. АRC - антиотражающее покрытие.

зовались пластины фосфида индия $n$-типа проводимости с кристаллографической ориентацией рабочей поверхности (100). Для насыщения расплава использовались нелегированные полупроводниковые материалы InP, InAs и GaAs. Гомогенизация раствора-расплава в отсутствие фосфора предварительно проводилась в течение часа при температуре $T=680^{\circ} \mathrm{C}$. После этого в кассету загружалась подготовленная подложка, а в расплав добавлялся источник фосфора. Температура роста четверных твердых растворов InGaAsP варьировалась в диапазоне от 600 до $650^{\circ} \mathrm{C}$. С целью предотвращения эрозии поверхности фосфида индия под воздействием высоких температур за счет испарения фосфора в эпитаксиальном процессе над подложкой создавалось избыточное давление паров фосфора. Для этого в кассете формировалась дополнительная ячейка с расплавом олова и фосфидом индия, не контактирующая непосредственно с подложкой в процессе эпитаксии, но позволяющая парам фосфора поступать к ее поверхности. Кроме того, непосредственно перед началом наращивания слоев фотоэлектрической

Письма в ЖТФ, 2018, том 44, вып. 18 
структуры верхний слой $(\leq 20 \mu \mathrm{m})$ подложки фосфида индия травился в недосыщенном расплаве олова.

Несмотря на то что принципы расчета фазовых диаграмм четверных твердых растворов $\mathrm{A}^{3} \mathrm{~B}^{5}$ со смешиванием компонентов в обеих подрешетках разработаны достаточно давно [7], результаты теоретического моделирования заметно расходятся с экспериментальными данными или требуют введения около десяти дополнительных независимых параметров для достижения приемлемой совместимости [8]. По результатам проведенных при помощи методов фотолюминесценции исследований выращенных в настоящей работе эпитаксиальных слоев InGaAsP при $E_{g} \approx 1.0-1.15 \mathrm{eV}$ расхождения между теоретическими и экспериментальными данными составили более $15 \%$. Решение проблемы несовершенства используемых для расчета термодинамических моделей возможно благодаря применению „эмпирических“ формул, подходящих для ограниченного диапазона температур эпитаксии и конкретной ориентации подложки. В работе [9] была предложена фазовая диаграмма, полученная эмпирическим путем для эпитаксиальных слоев InGaAsP, согласованных с подложкой $\operatorname{InP}(100)$ и выращенных в диапазоне температур от 570 до $660^{\circ} \mathrm{C}$, благодаря которой расхождение между шириной запрещенной зоны слоев InGaAsP в теории и на практике составило не более $5 \%$, что позволило контролируемо вырастить ряд твердых растворов с $E_{g}$ от 0.95 до $1.34 \mathrm{eV}$. Достигнутые значения рассогласований между эпитаксиальным слоем и подложкой в гетероструктурах $\operatorname{InP}(\mathrm{GaAs}) / \mathrm{InP}$, измеренные при помощи метода рентгеновской дифрактометрии, составили менее $\pm 0.01 \%$.

В случае задачи преобразования монохроматического излучения с длиной волны $\lambda=1.064 \mu \mathrm{m}$ в отличие, например, от солнечных элементов не требуется высокой фоточувствительности ФЭП в широком диапазоне длин волн. Поскольку при этом в полученных гетероструктурах эпитаксиальные слои InGaAsP более узкозонные, чем подложка, появляется возможность использовать в качестве широкозонного окна подложку фосфида индия (рис. $1, b$ ). В такой „инверсной“ структуре, т.е. при засветке с тыльной стороны, как известно, при прохождении излучения через относительно „толстую“ подложку возрастают оптические потери, связанные с поглощением на свободных носителях. Они также увеличиваются с ростом концентрации легирующей примеси в подложке, что в свою очередь дает возможность снизить уровень контактного сопротивления на границе с подложкой. Для исследования

3 Письма в ЖТФ, 2018, том 44, вып. 18 
зависимости пропускания фосфида индия от уровня легирования использовались пластины InP (100) толщиной $450 \pm 20 \mu \mathrm{m}$, легированные оловом или серой. Было найдено, что изменение уровня концентрации примеси в подложке от $n \sim 2 \cdot 10^{16}$ до $\sim 2 \cdot 10^{18} \mathrm{~cm}^{-3}$ приводит к падению пропускания на $3-5 \%$ для длины волны $\lambda=1.064 \mu \mathrm{m}$. Однако уровень легирования подложки как подконтактного слоя существенным образом влияет на величину последовательного сопротивления ФЭП, и при высоком уровне засветки именно омические потери будут вносить все больший вклад в общую величину потерь фотопреобразователя. Исходя из этого можно сделать вывод, что использование подложек InP с уровнем легирования $n \geq 5 \cdot 10^{17} \mathrm{~cm}^{-3}$ позволит создавать достаточно низкоомные контакты и может стать разумным компромиссом в поисках приемлемого баланса между оптическими и омическими потерями.

Поскольку на поглощение света подложкой InP также существенно влияет ее толщина, были проведены измерения пропускания излучения подложками с толщинами 450 и $350 \mu \mathrm{m}$. Исследования показали, что уменьшение толщины на 100-120 $\mu$ m позволяет повысить пропускание на $\sim 10 \%$ и соответственно снизить оптические потери преобразователя. Из этих соображений для выращивания фотоэлектрических структур на основе гетероструктур $\operatorname{InP}(\mathrm{GaAs}) / \mathrm{InP}$ использовались подложки с минимально возможной толщиной $d \sim 350 \pm 20 \mu \mathrm{m}$, характеризующиеся достаточно низкими потерями на поглощение света и обеспечивающие возможность работы с образцами при постростовых процессах, например фотолитографии.

Методом ЖФЭ был получен ряд образцов ФЭП на основе гетероструктур InGaAsP/InP. Толщина базового слоя $n$-InGaAsP(Sn) варьировалась от 1 до $5 \mu \mathrm{m}$, концентрация электронов составляла $(3-6) \cdot 10^{17} \mathrm{~cm}^{-3}$. Толщина эмиттерного слоя $p$-InGaAsP $(\mathrm{Mg})$ также изменялась в диапазоне от 1 до $5 \mu \mathrm{m}$ с концентрацией дырок в нем не менее $10^{19} \mathrm{~cm}^{-3}$. Необходимое количество примеси в расплаве и толщины слоев для двух типов структур (рис. $1, a, b)$ определялись экспериментально.

В „инверсной“ структуре с толщиной $n$-InGaAsP $(\mathrm{Sn}) \sim 4.5 \mu \mathrm{m}$ и $p$-InGaAsP $(\mathrm{Mg}) \sim 2 \mu \mathrm{m}$ был получен внутренний квантовый выход $\eta=0.84$ без просветляющего покрытия (рис. 2, $a$, кривая 1 ). Как видно из рис. $2, b$ (кривая 1 ), максимальная спектральная чувствительность составила $\sim 0.8 \mathrm{~A} / \mathrm{W}$ для длин волн монохроматического излучения от 1.18 до $1.24 \mu \mathrm{m}$. Хотя данная фотоэлектрическая структура не

Письма в ЖТФ, 2018, том 44, вып. 18 

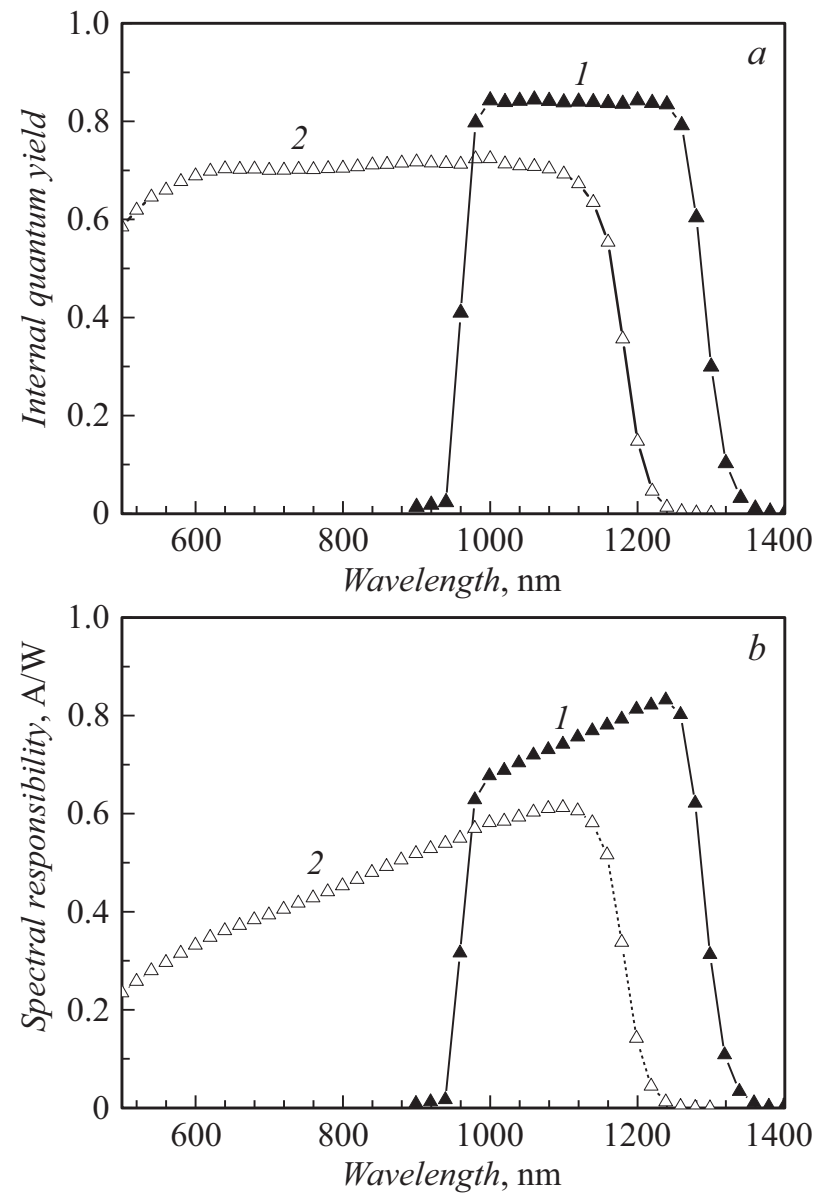

Рис. 2. Спектральные характеристики фотоответа двух образцов фотоэлектрического преобразователя лазерного излучения на основе гетероструктуры $p$-InGaAsP $(\mathrm{Mg}) / n$-InGaAsP $(\mathrm{Sn}) / n$-InP: 1 - „инверсная“ структура, где излучение падает со стороны подложки, 2 - „прямая“ структура, где излучение падает со стороны фронтального слоя.

оптимизирована для длины волны лазерного излучения $\lambda=1.064 \mu \mathrm{m}$, где спектральная фоточувствительность составила $\mathrm{SR}=0.73 \mathrm{~A} / \mathrm{W}$, тем

3* Письма в ЖТФ, 2018, том 44, вып. 18 

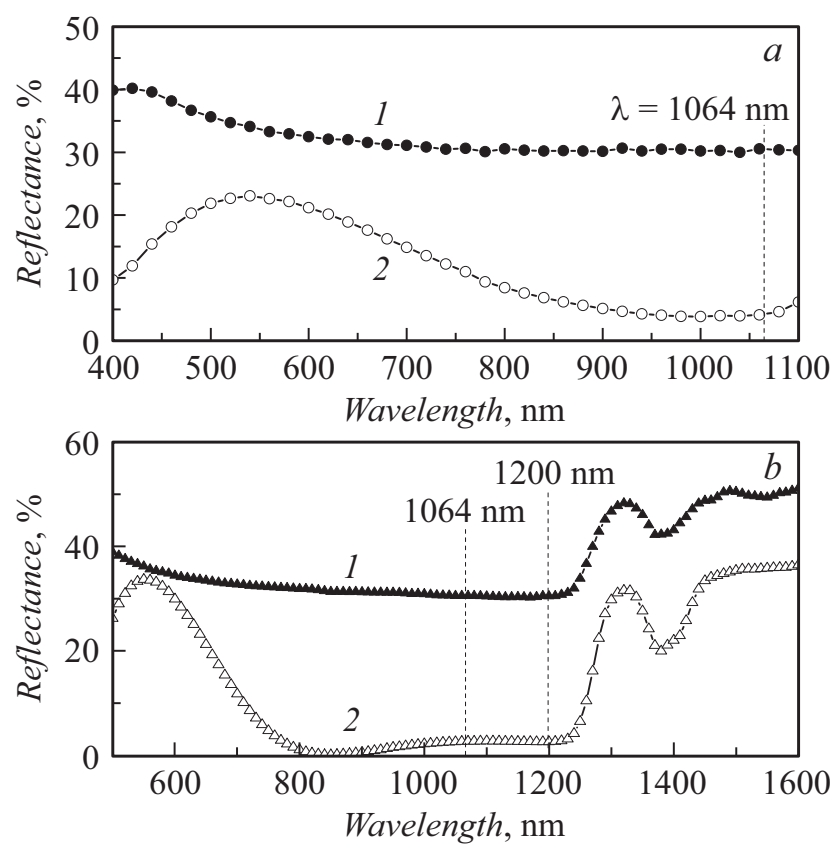

Рис. 3. Спектральные зависимости коэффициента отражения $R$ для гетероструктуры $\operatorname{InP}(\mathrm{GaAs}) / \mathrm{InP} . a-$ без анодного окисления $(1)$ и с просветляющим покрытием на основе анодного окисла $(2), b-$ без антиотражающего покрытия (1) и с просветляющим покрытием на основе $\mathrm{ZnS} / \mathrm{MgF}_{2}(2)$.

не менее такие ФЭП могут быть использованы для эффективного преобразования излучения полупроводниковых лазеров [10] с длиной волны $\sim 1.2 \mu \mathrm{m}$. В случае второй структуры внутренний квантовый выход для ФЭП на основе гетероструктуры $p$-InGaAsP $(\mathrm{Mg}) / n$-InGaAsP $(\mathrm{Sn}) / \mathrm{InP}$ составил $\eta=0.71$ (рис. 2, $a$, кривая 2) при засветке образца со стороны фронтального слоя. Более низкая квантовая эффективность „прямой“ фотоэлектрической структуры может объясняться отсутствием пассивации эмиттера широкозонным окном в отличие от „инверсной“ структуры. При этом спектральная чувствительность такого ФЭП, как следует из рисунка, хорошо согласуется с длиной волны генерации лазера $\lambda=1.064 \mu \mathrm{m}$ и составляет $\mathrm{SR}=0.61 \mathrm{~A} / \mathrm{W}$ (рис. $2, b$, кривая 2).

Письма в ЖТФ, 2018, том 44, вып. 18 
Как известно, достаточно большой вклад в эффективность работы фотопреобразователя вносят просветляющие покрытия. В качестве просветляющих покрытий были исследованы как однослойные покрытия (пленки собственного оксида), так и двухслойные антиотражающие покрытия (АОП) на основе $\mathrm{ZnS} / \mathrm{MgF}_{2}$, полученные путем термического испарения в вакууме и нанесенные на выращенные методом ЖФЭ гетероструктуры InGaAsP/InP. На рис. 3, $a$ показан пример АОП для „прямой“ структуры на основе пленки собственного оксида, получаемого анодированием в электролите. При анодном окислении в качестве электролита использовался $3 \%$ водный раствор винной кислоты с этиленгликолем в соотношении $1: 2$ с добавлением $\mathrm{NH}_{4} \mathrm{OH}$. Толщина оксида прецизионно регулируется подаваемым на структуру напряжением в процессе анодирования, что изменяет и спектральное распределение коэффициента отражения АОП. Для длины волны $\lambda=1.064 \mu \mathrm{m}$ минимальное отражение $R \sim 4 \%$ достигается при постепенном увеличении напряжения на структуре до $120 \mathrm{~V}$ (рис. 3, $a$, кривая 2). Нанесение двухслойного АОП на основе $\mathrm{ZnS} / \mathrm{MgF}_{2}$ термическим испарением в вакууме позволяет снизить значение отражения $R$ до $\sim 2.7 \%$ (рис. $3, b$, кривая 2 ) для „инверсной“ и „прямой“ структур. За счет расширенного спектра фоточувствительности ФЭП на базе гетероструктур $\mathrm{InP}(\mathrm{GaAs}) / \mathrm{InP}$ c таким АОП могут использоваться для эффективной работы в более широком диапазоне длин волн от 0.92 до $1.20 \mu \mathrm{m}$.

Таким образом, в работе показано, что использование эмпирических зависимостей фазовой диаграммы системы $\mathrm{InP}(\mathrm{GaAs}) / \mathrm{InP}$ позволяет получать фотоэлектрические структуры, обеспечивающие высокую квантовую эффективность фотоответа для лазерного излучения с длинами волн $\lambda=1.064 \mu \mathrm{m}(71 \%)$ и $\lambda=1.2 \mu \mathrm{m}(84 \%)$ и высокую эффективность систем беспроводной передачи энергии. Наилучшие характеристики в разработанных структурах с эпитаксиальным $p-n$-переходом были достигнуты для случая засветки со стороны подложки фосфида индия, используемой в качестве широкозонного окна, с уровнем легирования $n \geq 5 \cdot 10^{17} \mathrm{~cm}^{-3}$ и толщиной не более $350 \mu \mathrm{m}$. Показано, что оптимизация просветляющих покрытий с использованием анодного окисла и двухслойного антиотражающего покрытия $\left(\mathrm{ZnS} / \mathrm{MgF}_{2}\right)$ дает возможность снижения коэффициента отражения падающего излучения от поверхности фотопреобразователя до 3-4\% для обоих типов структур ФЭП (,прямой“ и „инверсной“ $)$.

Письма в ЖТФ, 2018, том 44, вып. 18 


\section{Список литературы}

[1] Schafer C.A., Gray D. // Acta Astron. 2012. V. 79. P. 140-156.

[2] Williams M.D., De Young R.J., Schuster G.L., Choi S.H., Dagle J.E., Coomes E.P., Antoniak Z.I., Bamberger J.A., Bates J.M., Chiu M.A., Dodge R.E., Wise J.A. Power transmission by laser beam from Lunar-synchronous satellite. NASA, 1993. TM-4496. $31 \mathrm{p}$.

[3] Хвостиков В.П., Сорокина С.В., Потапович Н.С., Хвостикова О.А., Тимошина Н.X. // ФТП. 2017. Т. 51. В. 5. С. 676-679.

[4] Summerer L., Purcell O. Concepts for wireless energy transmission via laser // Int. Conf. on space optical systems and applications. 2009. https://www.esa.int/gsp/ACT/doc/POW/ACT-RPR-NRG-2009-SPS-ICSOSconcepts-for-laser-WPT.pdf

[5] Saiki T., Fujiwara N., Matsuoka N., Nakatuka M., Fujioka K., Iida Y. // Opt. Commun. 2017. V. 387. P. 316-321.

[6] Nakajima K. // Semiconductors and semimetals. 1985. V. 22. Pt A. P. 2.

[7] Jordan A.S., Iligems M. // J. Phys. Chem. Solids. 1975. V. 36. P. 329-342.

[8] Perea E.H., Fonstad C.G. // J. Appl. Phys. 1980. V. 51. P. 331-335.

[9] Kuphal E. // Appl. Phys. A. 1991. V. 52. P. 380-409.

[10] Винокуров Д.А., Николаев Д.Н., Пихтин Н.А., Станкевич А.Л., Шамахов В.В., Растегаева М.Г., Рожков А.В., Тарасов И.С. // ФТП. 2010. Т. 44. B. 12 . C. $1640-1644$. 